Review

\title{
A systematic review of sleep disorders in patients with chronic kidney disease undergoing hemodialysis
}

Nina Teixeira Fonseca, PT, MSc ${ }^{1)}$, Jessica Julioti Urbano, PT ${ }^{1)}$, Sergio Roberto Nacif, MD, PhD ${ }^{1)}$, Anderson Soares Silva, PT ${ }^{1)}$, Roger Andre Oliveira Peixoto, PT, MSc1), Giovanni Julioti Urbano, BSc ${ }^{1)}$, Ezequiel Fernandes Oliveira, PT, MSc ${ }^{1)}$, Israel Reis Santos, PT, MSc ${ }^{1)}$, Claudia Santos Oliveira, PT, $\mathrm{PhD}^{1}$, Giuseppe Insalaco, MD, $\mathrm{PhD}^{2)}$, Luis Vicente Franco Oliveira, PT, $\mathrm{PhD}^{1)^{*}}$

1) Sleep Laboratory, Rehabilitation Sciences Master's and PhD Degree Program, Nove de Julho University, UNINOVE: Rua Vergueiro, 235/249, Sao Paulo, CEP 01504-001, Brazil

2) Institute of Biomedicine and Molecular Immunology, National Research Council of Italy, Italy

\begin{abstract}
Purpose] The purpose of this study was to conduct a systematic review of the available evidence on sleep disorders in patients with end stage renal disease (ESRD) undergoing hemodialysis (HD). [Subjects and Methods] Two independent reviewers performed a computer-assisted search of the MEDLINE, SciELO, LILACS, and BIREME Virtual Health Library medical databases from their inception to November 2015. [Results] One thousand one hundred twenty-six articles were found that met the inclusion criteria. Articles were excluded if they were not in English, the patients did not undergo HD, or the studies were not cross-sectional or clinical trials. After reading the full text, a further 300 studies were excluded because they did not use polysomnography. The remaining 18 studies with ESRD patients undergoing HD comprised 8 clinical trials and 10 cross-sectional studies. This systematic review followed the criteria outlined by the PRISMA declaration. [Conclusion] In this systematic review, a high prevalence of sleep disorders was observed in ESRD, including sleep-disordered breathing. This knowledge may enable health professionals to devise new strategies for the diagnosis and treatment of these patients, in order to reduce morbidity and mortality and improve their quality of life.

Key words: Sleep disorders, Chronic kidney disease, Hemodialysis
\end{abstract}

(This article was submitted Dec. 17, 2015, and was accepted Apr. 7, 2016)

\section{INTRODUCTION}

Currently, chronic kidney disease (CKD) is one of the most serious public health problems. Some recent epidemiological studies have suggested that approximately one million people with end stage renal disease (ESRD) undergo replacement therapy worldwide. The increased prevalence of CKD in the developed and developing countries threatens to become a global epidemic, as exemplified by the increased number of cases of diabetes mellitus and the increased life expectancy of the population ${ }^{1)}$. CKD severely affects patients' health, lifestyle and wellbeing, compromising their quality of life ${ }^{2)}$. According Ponngeon et al., CKD patients had "sedentary" and "inactive" levels of physical activity on dialysis and non-dialysis days, respectively ${ }^{3)}$. Silva and Marinho observed that the level of physical activity of most patients ESRD undergoing hemodialysis is poor and that most do not perform exercise regularly ${ }^{4}$. The most common comorbidities observed in patients with CKD are diabetes mellitus type $2^{1)}$, dyslipidemia, coronary heart disease, heart failure ${ }^{5,6)}$, hypertension ${ }^{7,8)}$, respiratory disorders ${ }^{8,9)}$, stress $^{10)}$, depression ${ }^{10-12)}$, anxiety ${ }^{13)}$, and obstructive sleep apnea (OSA) ${ }^{14)}$.

*Corresponding author. Luis Vicente Franco Oliveira (E-mail: oliveira.lvf@uninove.br)

(C2016 The Society of Physical Therapy Science. Published by IPEC Inc.

This is an open-access article distributed under the terms of the Creative Commons Attribution Non-Commercial No Derivatives (by-nc-nd) License $<$ http://creativecommons.org/licenses/by-nc-nd/4.0/>. 
OSA is a major medical problem, estimated to affect up to $15-30 \%$ of male adults and up to $5-15 \%$ of female adults ${ }^{15,16)}$. It is characterized by repetitive obstructions of the upper airway during sleep, frequently causing oxygen desaturation. This induces frequent awakenings (arousals), resulting in fragmented sleep and excessive daytime sleepiness.

In Brazil, according to a recent epidemiological study conducted in São Paulo, an OSA prevalence of $24.8 \%$ in men and $9.6 \%$ in women was observed, based on an apnea-hypopnea index (AHI) $\geq 15$ events $/ \mathrm{h}$; for an AHI $\geq 5$ events $/ \mathrm{h}$, this prevalence increased to $40 \%$ in men and $26 \%$ in women ${ }^{17}$. In a recent study involving 2,121 individuals conducted in the city of Lausanne in Switzerland, a prevalence of $50 \%$ in men and $23 \%$ in women was observed, based on an AHI $\geq 15$ events/ $\mathrm{h}^{18)}$. In another study conducted by Oliveira et al., patients with neuromuscular disorders such as myasthenia gravis were observed to have a poor quality of sleep, excessive daytime sleepiness, presence of restless syndrome, and a high incidence of sleep-disordered breathing (SDB) ${ }^{19}$.

The prevalence of sleep disorders among patients with CKD is $40-80 \%$, which is higher than that among the general population. Among these sleep disorders, the presence of periodic leg movements during sleep and OSA has been highlighted ${ }^{20)}$.

The high prevalence $(50 \%)$ of SDB in patients undergoing hemodialysis (HD) can be attributed to compromised upper airway stability (extracellular fluid volume overload) ${ }^{21-23)}$, ventilatory control instability (altered central and peripheral chemosensitivity), and reduced upper airway muscle tone (uremia) ${ }^{24-28)}$. Risk factors of SDB in the general population, such as older age, male gender, obesity, smoking, increased neck circumference, and diabetes, are also prevalent in the CKD population $^{29)}$.

SDB has been associated with increased cardiovascular risk, and may contribute to the morbidity and mortality of patients with advanced (stages 4 to 5) CKD or those undergoing $\mathrm{HD}^{30)}$.

Although numerous studies have shown that a substantial proportion of patients undergoing HD have sleep apnea, these studies were limited by the following factors: very small sample sizes ${ }^{27,31-34)}$; the use of partial channel polysomnography (PSG) ${ }^{34-36)}$; the study of populations with limited generalizability to patients undergoing $\mathrm{HD}^{37}$; ; a selected subpopulation of patients undergoing dialysis, without sleep symptoms ${ }^{38)}$; or study samples that were largely composed of symptomatic patients $^{26,31,39)}$. Hence, a better understanding of the prevalence and risk factors of SDB in CKD patients undergoing HD is critical. Therefore, a systematic review that can demonstrate the status of the knowledge is justified. This knowledge may enable health professionals, especially physiotherapists, to devise new strategies to reduce morbidity and mortality and improve the quality of life of CKD patients. The present study aimed to provide a thorough overview of the literature regarding the occurrence of sleep disorders in patients with ESRD undergoing HD.

\section{SUBJECTS AND METHODS}

Two independent reviewers performed a computer-assisted search of the MEDLINE, LILACS, and SciELO Virtual Health Library medical databases from their inception to November 2015. A combination of the following Medical Subject Headings (MeSH) were used in the search ("sleep" OR "sleep disorders" OR "obstructive sleep apnea") AND ("kidney dialysis" OR "hemodialysis" OR "dialysis").

The first stage of the search identified articles according to the title, abstract, and key words. In the second stage, the contents of the manuscripts were evaluated. Articles that involved patients $>18$ years old, having ESRD and undergoing HD, and that used overnight standard PSG for the diagnosis of sleep disorders, were included in the final analysis. This systematic review followed the criteria outlined in the PRISMA declaration ${ }^{40)}$.

\section{RESULTS}

One thousand one hundred twenty-six articles were identified that met the inclusion criteria. A total of 796 articles were excluded because they were not in English, the patients did not undergo HD, or the studies were not cross-sectional or clinical trials. After an evaluation of the full text, 312 studies were excluded, either because PSG was not performed or they were duplicated. The remaining 18 studies, comprising 8 clinical trials and 10 cross-sectional studies, were included for further examination (Fig. 1). The results and outcomes of all included studies are summarized in Tables 1 and 2 and are discussed below. Thus, a detailed analysis of 18 articles that used overnight PSG, which is considered the gold standard method for the diagnosis of sleep disorders, was conducted.

\section{DISCUSSION}

The aim of this study was to conduct a systematic review of studies showing the presence of sleep disorders in patients with ESRD undergoing HD.

The presence of sleep disorders, including SDB, Periodic Limb Movement Disorder (PLMD) and/or Restless Legs Syndrome (RLS), which compromise the quality of life and increase the morbidity and mortality rates of patients with CKD, has been documented in the literature ${ }^{50-53)}$. Seventy percent of ESRD patients are believed to have some form of SDB ${ }^{26,39)}$. RLS is a common and extremely distressing problem experienced by many patients undergoing HD. It is a neurological condition characterized by an irresistible urge to move the legs and occurs more frequently during inactivity and at night ${ }^{54,55)}$. 


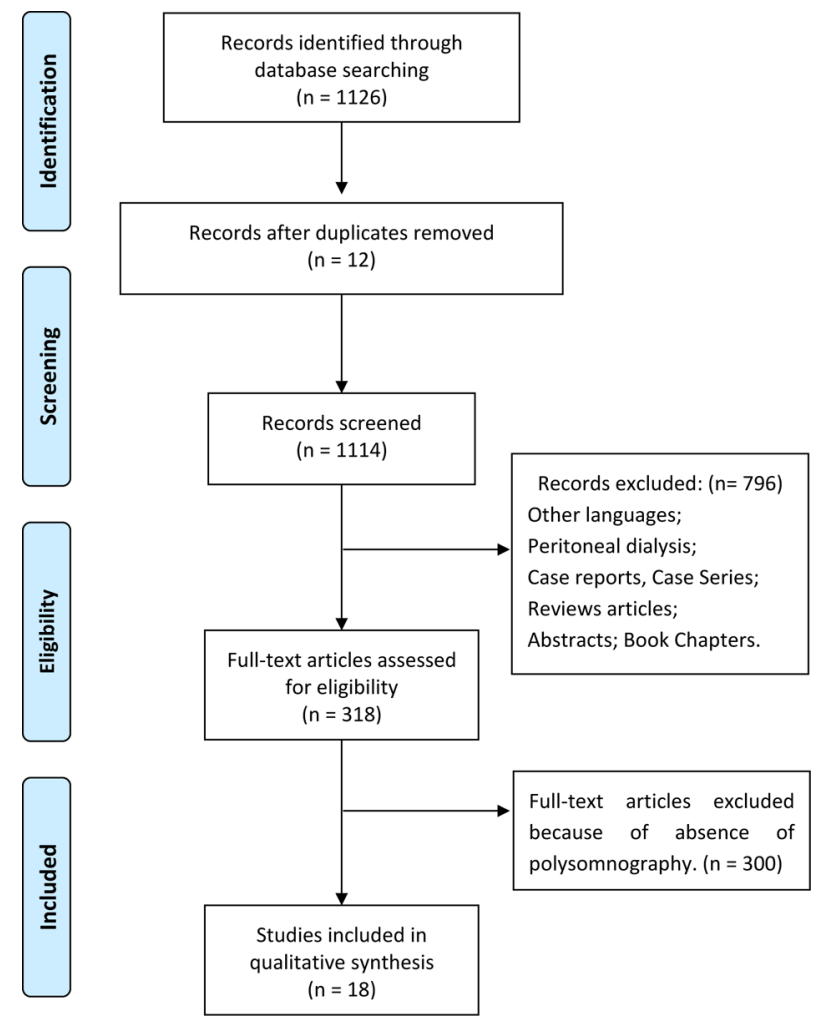

Fig. 1. Flowchart of the study

The prevalence of RLS in patients who are under treatment with HD varies across studies performed in broad geographical regions (6.6-68\%), and recent studies using the International RLS Study Group criteria have suggested a prevalence rate of $33 \%$ in ESRD patients, which is greater than that in the general population ${ }^{56)}$.

Sleep fragmentation and sleep deprivation caused by RLS may contribute to cardiovascular complications and infections, often with poor prognosis in patients undergoing HD. According to the literature, patients undergoing HD have a poorer quality of sleep compared to the normal population. The presence of RLS and associated sleep disorders, such as daytime sleepiness, insomnia, and poor sleep quality, should be considered a problem that further impairs the quality of life of patients. Studies have demonstrated that $40-80 \%$ of ESRD patients undergoing HD suffer from poor sleep quality associated with a poor quality of life ${ }^{57,58)}$. Sleep disorders are usually associated with physical, behavioral, and psychological disorders that predispose to cognitive impairment, decline in social performance and interpersonal interactions, and depression ${ }^{59)}$.

$\mathrm{SDB}$ is very common among patients with $\mathrm{CKD}$, especially those undergoing $\mathrm{HD}^{36,60)}$. Some studies have suggested OSA has a prevalence of 50-60\% in ESRD patients ${ }^{12,61)}$. Depending on the methodology applied, approximately $50-80 \%$ of CKD patients have some form of $\mathrm{SDB}^{26,39)}$. OSA is 4 to 10 times more prevalent among CKD patients than in the general population $^{22,49)}$. A more recent study conducted by Nicholls et al. involving 254 CKD patients showed a significant increase in the occurrence of SDB (predominantly OSA) which was related to impairment of renal function, with a prevalence of $57 \%{ }^{62}$.

This study utilized only studies performed using PSG, considered the gold standard for the diagnosis of sleep disorders. Despite the high prevalence of sleep disorders in the CKD population, there is limited scientific research on the topic, as evidenced by only as shown by 18 studies (10 cross-sectional studies and 8 controlled clinical trials) having been retrieved in this review. This is perhaps explained by the high cost of PSG examination, or by a lack of knowledge about the presence of sleep disorders in CKD population.

Other more viable diagnostic methods, such as pulse oximetry and specific validated sleep questionnaires, could be used as screening tools for the presence of SDB, aiding in the early diagnosis and choice of appropriate treatment with noninvasive ventilatory support.

Epidemiological studies have shown a strong and intrinsic relationship between CKD and OSA. ESRD contributes to the emergence and/or development of OSA due to factors such as metabolic acidosis, compromised sensitivity of chemoreceptors, uremic toxins, generalized muscle weakness, particularly of the dilator muscles of the pharynx, and narrowing of the upper airway due to fluid accumulation in the interdialytic period. It is known that OSA induces CKD due to increased blood pressure, oxidative stress, and repetitive hypoxia. Therefore, OSA is a major risk factor for CKD.

This systematic review verified the status of knowledge regarding the prevalence of sleep disorders in ESRD patients 


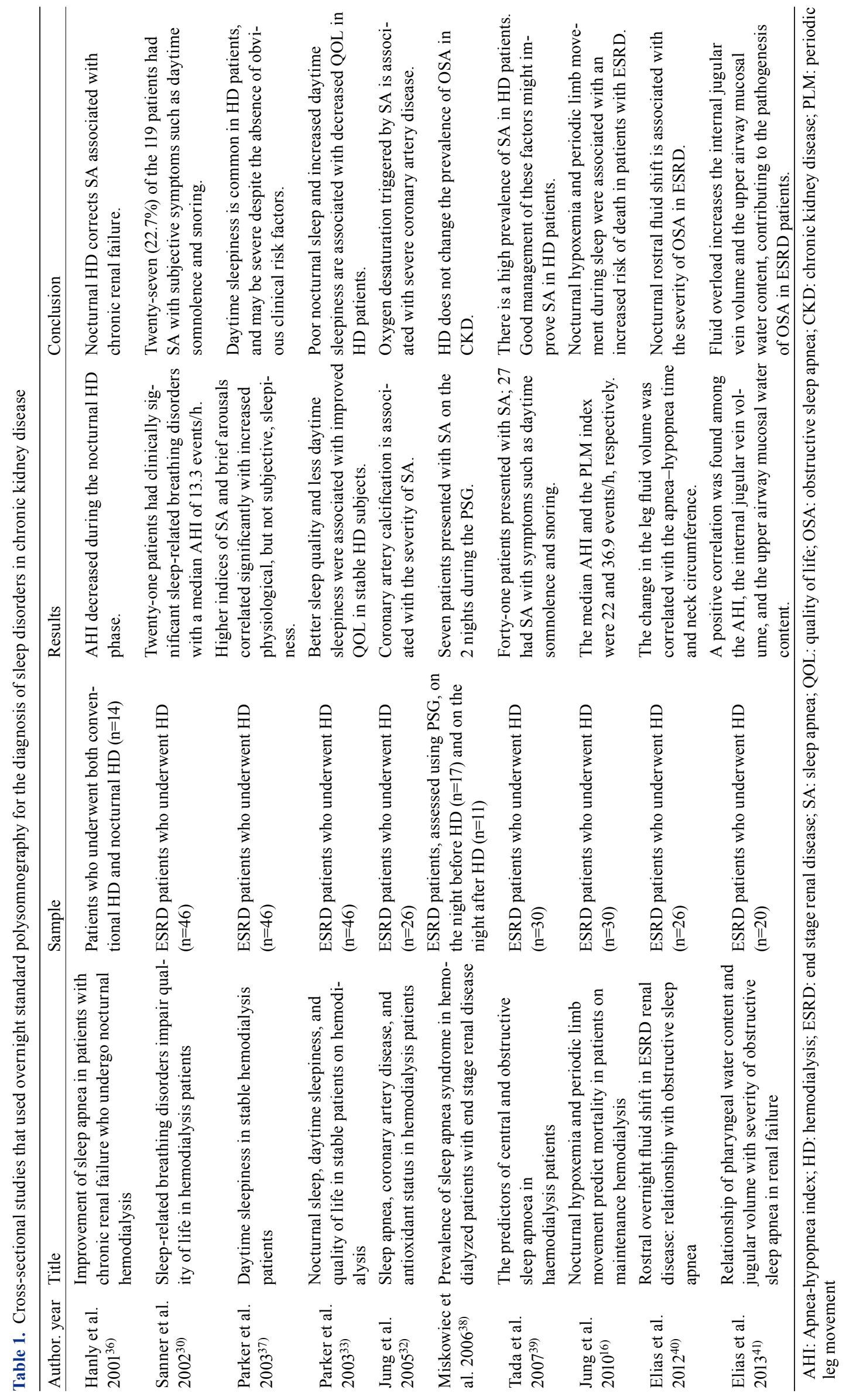




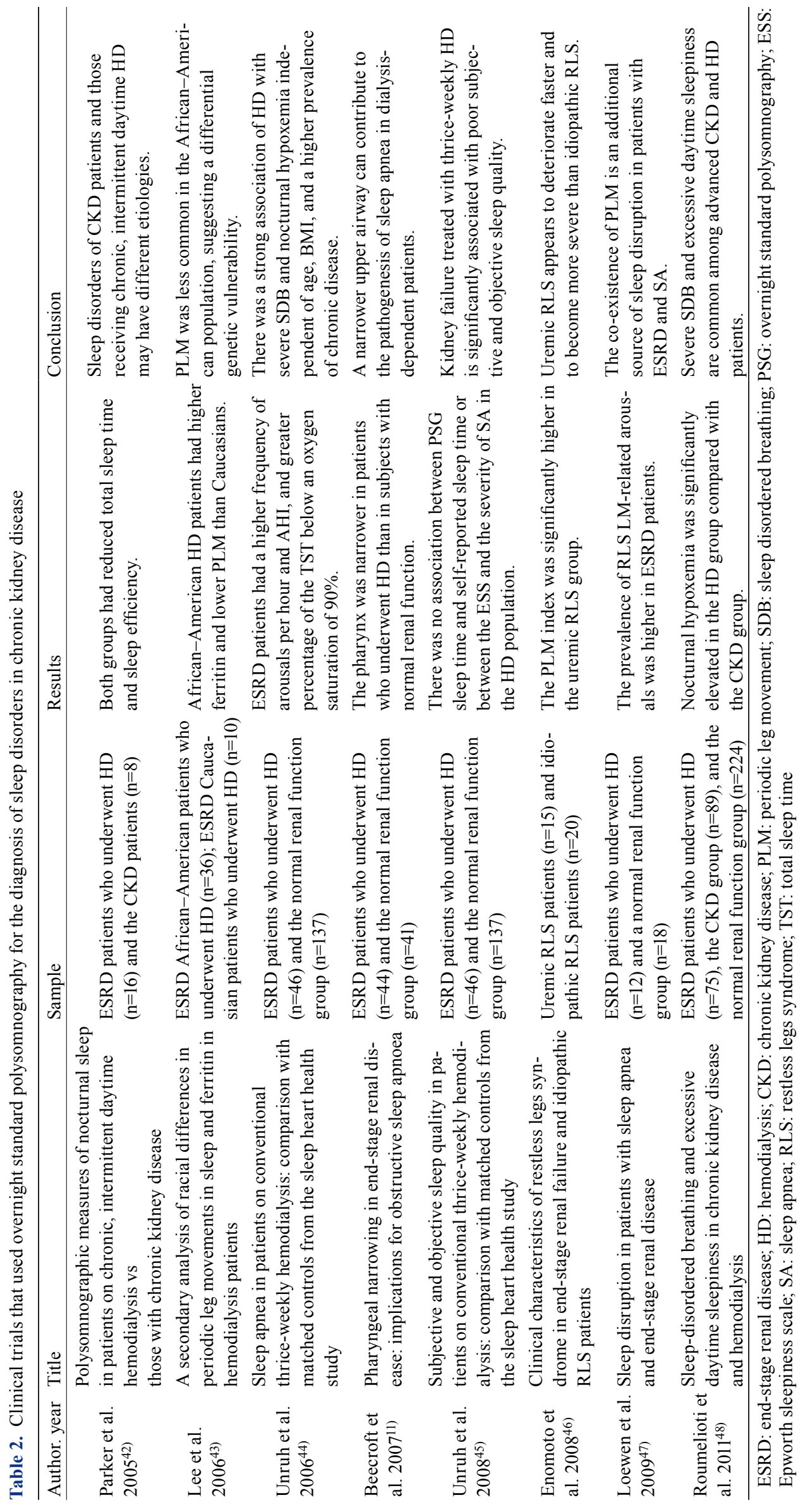


undergoing HD. According to the studies analyzed, a high prevalence of PLMD, RLS, and OSA affecting the quality of sleep was observed, which in turn undermined the quality of life of these patients, leading to increased morbidity and mortality.

Thus, it is very important for healthcare professionals to recognize the signs and symptoms of sleep disorders in CKD patient population, both for accurate diagnosis and an appropriate therapeutic approach. For physical therapists, it is extremely important to identify SDB, particularly OSA, so they can institute treatment with continuous positive airway pressure.

\section{REFERENCES}

1) Jurkovitz CT, Elliott D, Li S, et al. KEEP Investigators: Physician utilization, risk-factor control, and CKD progression among participants in the Kidney Early Evaluation Program (KEEP). Am J Kidney Dis, 2012, 59: S24-S33. [Medline] [CrossRef]

2) Bae YH, Lee SM, Jo JI, et al.: Aerobic training during hemodialysis improves body composition, muscle function, physical performance, and quality of life in chronic kidney disease patients. J Phys Ther Sci, 2015, 27: 1445-1449. [Medline] [CrossRef]

3) Ponngeon O, Chaunchaiyakul R, Vareesangthip K, et al.: Home-based walking program increases leg muscle strength in hemodialysis patients. J Phys Ther Sci, 2011, 23: 345-348. [CrossRef]

4) Silva LC, Marinho PE: Knowledge among nephrologists about the importance of exercise in the intradialytic period. J Phys Ther Sci, 2015, 27: 2991-2994. [Medline] [CrossRef]

5) Zoccali C, Mallamaci F, Tripepi G: Novel cardiovascular risk factors in end-stage renal disease. J Am Soc Nephrol, 2004, 15: S77-S80. [Medline] [CrossRef]

6) Weiner DE, Tighiouart H, Stark PC, et al.: Kidney disease as a risk factor for recurrent cardiovascular disease and mortality. Am J Kidney Dis, 2004, 44: 198-206. [Medline] [CrossRef]

7) Drager LF, Bortolotto LA, Krieger EM, et al.: Additive effects of obstructive sleep apnea and hypertension on early markers of carotid atherosclerosis. Hypertension, 2009, 53: 64-69. [Medline] [CrossRef]

8) Nieto FJ, Young TB, Lind BK, et al.: Association of sleep-disordered breathing, sleep apnea, and hypertension in a large community-based study. Sleep Heart Health Study. JAMA, 2000, 283: 1829-1836. [Medline] [CrossRef]

9) McIntyre CW, Selby NM, Sigrist M, et al.: Patients receiving maintenance dialysis have more severe functionally significant skeletal muscle wasting than patients with dialysis-independent chronic kidney disease. Nephrol Dial Transplant, 2006, 21: 2210-2216. [Medline] [CrossRef]

10) Miyazaki ET, Dos Santos R Jr, Miyazaki MC, et al.: Patients on the waiting list for liver transplantation: caregiver burden and stress. Liver Transpl, 2010, 16: 1164-1168. [Medline] [CrossRef]

11) Chilcot J, Wellsted D, Farrington K: Screening for depression while patients dialyse: an evaluation. Nephrol Dial Transplant, 2008, 23: 2653-2659. [Medline] [CrossRef]

12) Kimmel PL, Peterson RA, Weihs KL, et al.: Multiple measurements of depression predict mortality in a longitudinal study of chronic hemodialysis outpatients Kidney Int, 2000, 57: 2093-2098. [Medline] [CrossRef]

13) Faries D, Herrera J, Rayamajhi J, et al.: The responsiveness of the Hamilton Depression Rating Scale. J Psychiatr Res, 2000, 34: 3-10. [Medline] [CrossRef]

14) Beecroft JM, Hoffstein V, Pierratos A, et al.: Pharyngeal narrowing in end-stage renal disease: implications for obstructive sleep apnoea. Eur Respir J, 2007, 30: 965-971. [Medline] [CrossRef]

15) Young T, Palta M, Dempsey J, et al.: Burden of sleep apnea: rationale, design, and major findings of the Wisconsin Sleep Cohort study. WMJ, 2009, 108: 246-249. [Medline]

16) Peppard PE, Young T, Barnet JH, et al.: Increased prevalence of sleep-disordered breathing in adults. Am J Epidemiol, 2013, 177: 1006-1014. [Medline] [CrossRef]

17) Tufik S, Santos-Silva R, Taddei JA, et al.: Obstructive sleep apnea syndrome in the Sao Paulo Epidemiologic Sleep Study. Sleep Med, 2010, 11: 441-446. [Medline] [CrossRef]

18) Heinzer R, Vat S, Marques-Vidal P, et al.: Prevalence of sleep-disordered breathing in the general population: the HypnoLaus study. Lancet Respir Med, 2015, 3: 310-318. [Medline] [CrossRef]

19) Fernandes Oliveira E, Nacif SR, Alves Pereira N, et al.: Sleep disorders in patients with myasthenia gravis: a systematic review. J Phys Ther Sci, 2015, 27: 2013-2018. [Medline] [CrossRef]

20) Jung HH, Lee JH, Baek HJ, et al.: Nocturnal hypoxemia and periodic limb movement predict mortality in patients on maintenance hemodialysis. Clin J Am Soc Nephrol, 2010, 5: 1607-1613. [Medline] [CrossRef]

21) Hanly P: Sleep apnea and daytime sleepiness in end-stage renal disease. Semin Dial, 2004, 17: 109-114. [Medline] [CrossRef]

22) Beecroft JM, Pierratos A, Hanly PJ: Clinical presentation of obstructive sleep apnea in patients with end-stage renal disease. J Clin Sleep Med, 2009, 5: 115-121. [Medline]

23) Noguchi M, Yamaguchi S, Koshino Y, et al.: Validity of body impedance analysis for evaluating body composition in patients undergoing long-term hemodialysis. J Phys Ther Sci, 2015, 27: 1649-1652. [Medline] [CrossRef]

24) Kraus MA, Hamburger RJ: Sleep apnea in renal failure. Adv Perit Dial, 1997, 13: 88-92. [Medline]

25) Zoccali C, Mallamaci F, Tripepi G: Sleep apnea in renal patients. J Am Soc Nephrol, 2001, 12: 2854-2859. [Medline]

26) Kimmel PL, Miller G, Mendelson WB: Sleep apnea syndrome in chronic renal disease. Am J Med, 1989, 86: 308-314. [Medline] [CrossRef]

27) Mendelson WB, Wadhwa NK, Greenberg HE, et al.: Effects of hemodialysis on sleep apnea syndrome in end-stage renal disease. Clin Nephrol, 1990, 33: 247-251. [Medline]

28) Fletcher EC: Obstructive sleep apnea and the kidney. J Am Soc Nephrol, 1993, 4: 1111-1121. [Medline]

29) Young T, Shahar E, Nieto FJ, et al. Sleep Heart Health Study Research Group: Predictors of sleep-disordered breathing in community-dwelling adults: the Sleep Heart Health Study. Arch Intern Med, 2002, 162: 893-900. [Medline] [CrossRef]

30) Zoccali C, Mallamaci F, Tripepi G: Nocturnal hypoxemia predicts incident cardiovascular complications in dialysis patients. J Am Soc Nephrol, 2002, 13: 
729-733. [Medline]

31) Benz RL, Pressman MR, Hovick ET, et al.: A preliminary study of the effects of correction of anemia with recombinant human erythropoietin therapy on sleep, sleep disorders, and daytime sleepiness in hemodialysis patients (The SLEEPO study). Am J Kidney Dis, 1999, 34: 1089-1095. [Medline] [CrossRef]

32) Chan CT, Hanly P, Gabor J, et al.: Impact of nocturnal hemodialysis on the variability of heart rate and duration of hypoxemia during sleep. Kidney Int, 2004, 65: 661-665. [Medline] [CrossRef]

33) Wadhwa NK, Mendelson WB: A comparison of sleep-disordered respiration in ESRD patients receiving hemodialysis and peritoneal dialysis. Adv Perit Dial, 1992, 8: 195-198. [Medline]

34) Venmans BJ, van Kralingen KW, Chandi DD, et al.: Sleep complaints and sleep disordered breathing in hemodialysis patients. Neth J Med, 1999, 54: $207-212$. [Medline] [CrossRef]

35) Sanner BM, Tepel M, Esser M, et al.: Sleep-related breathing disorders impair quality of life in haemodialysis recipients. Nephrol Dial Transplant, 2002, 17: 1260-1265. [Medline] [CrossRef]

36) Kuhlmann U, Becker HF, Birkhahn M, et al.: Sleep-apnea in patients with end-stage renal disease and objective results. Clin Nephrol, 2000 , 53: 460-466. [Medline]

37) Jung HH, Han H, Lee JH: Sleep apnea, coronary artery disease, and antioxidant status in hemodialysis patients. Am J Kidney Dis, 2005, 45: 875-882. [Medline] [CrossRef]

38) Parker KP, Kutner NG, Bliwise DL, et al.: Nocturnal sleep, daytime sleepiness, and quality of life in stable patients on hemodialysis. Health Qual Life Outcomes, 2003, 1: 68. [Medline] [CrossRef]

39) Millman RP, Kimmel PL, Shore ET, et al.: Sleep apnea in hemodialysis patients: the lack of testosterone effect on its pathogenesis. Nephron, 1985, 40: 407-410. [Medline] [CrossRef]

40) Liberati A, Altman DG, Tetzlaff J, et al. PRISMA Group: The PRISMA statement for reporting systematic reviews and meta-analyses of studies that evaluate healthcare interventions: explanation and elaboration. BMJ, 2009, 339: b2700. [Medline] [CrossRef]

41) Hanly PJ, Pierratos A: Improvement of sleep apnea in patients with chronic renal failure who undergo nocturnal hemodialysis. N Engl J Med, 2001, 344: 102-107. [Medline] [CrossRef]

42) Parker KP, Bliwise DL, Bailey JL, et al.: Daytime sleepiness in stable hemodialysis patients. Am J Kidney Dis, 2003, 41: 394-402. [Medline] [CrossRef]

43) Miśkowiec I, Klawe JJ, Tafil-Klawe M, et al.: Prevalence of sleep apnea syndrome in hemodialyzed patients with end-stage renal disease. J Physiol Pharmacol, 2006, 57: 207-211. [Medline]

44) Tada T, Kusano KF, Ogawa A, et al.: The predictors of central and obstructive sleep apnoea in haemodialysis patients. Nephrol Dial Transplant, 2007, 22: 1190-1197. [Medline] [CrossRef]

45) Elias RM, Bradley TD, Kasai T, et al.: Rostral overnight fluid shift in end-stage renal disease: relationship with obstructive sleep apnea. Nephrol Dial Transplant, 2012, 27: 1569-1573. [Medline] [CrossRef]

46) Elias RM, Chan CT, Paul N, et al.: Relationship of pharyngeal water content and jugular volume with severity of obstructive sleep apnea in renal failure. Nephrol Dial Transplant, 2013, 28: 937-944. [Medline] [CrossRef]

47) Parker KP, Bliwise DL, Bailey JL, et al.: Polysomnographic measures of nocturnal sleep in patients on chronic, intermittent daytime haemodialysis vs those with chronic kidney disease. Nephrol Dial Transplant, 2005, 20: 1422-1428. [Medline] [CrossRef]

48) Lee JH, Parker KP, Ansari FP, et al.: A secondary analysis of racial differences in periodic leg movements in sleep and ferritin in hemodialysis patients. Sleep Med, 2006, 7: 646-648. [Medline] [CrossRef]

49) Unruh ML, Sanders MH, Redline S, et al.: Sleep apnea in patients on conventional thrice-weekly hemodialysis: comparison with matched controls from the Sleep Heart Health Study. J Am Soc Nephrol, 2006, 17: 3503-3509. [Medline] [CrossRef]

50) Unruh ML, Sanders MH, Redline S, et al.: Subjective and objective sleep quality in patients on conventional thrice-weekly hemodialysis: comparison with matched controls from the sleep heart health study. Am J Kidney Dis, 2008, 52: 305-313. [Medline] [CrossRef]

51) Enomoto M, Inoue Y, Namba K, et al.: Clinical characteristics of restless legs syndrome in end-stage renal failure and idiopathic RLS patients. Mov Disord, 2008, 23: 811-816, quiz 926. [Medline] [CrossRef]

52) Loewen A, Siemens A, Hanly P: Sleep disruption in patients with sleep apnea and end-stage renal disease. J Clin Sleep Med, 2009, 5: 324-329. [Medline]

53) Roumelioti ME, Buysse DJ, Sanders MH, et al.: Sleep-disordered breathing and excessive daytime sleepiness in chronic kidney disease and hemodialysis. Clin J Am Soc Nephrol, 2011, 6: 986-994. [Medline] [CrossRef]

54) Kavanagh D, Siddiqui S, Geddes CC: Restless legs syndrome in patients on dialysis. Am J Kidney Dis, 2004, 43: 763-771. [Medline] [CrossRef]

55) Molnar MZ, Novak M, Szeifert L, et al.: Restless legs syndrome, insomnia, and quality of life after renal transplantation. J Psychosom Res, 2007, 63: 591-597. [Medline] [CrossRef]

56) Kathy P, Mark U: ERSD patient handout patient guide to End-Stage Renal Disease (ESRD) and RLS. Night Walkers, 2008, Summer: 21-22.

57) Elder SJ, Pisoni RL, Akizawa T, et al.: Sleep quality predicts quality of life and mortality risk in haemodialysis patients: results from the Dialysis Outcomes and Practice Patterns Study (DOPPS). Nephrol Dial Transplant, 2008, 23: 998-1004. [Medline] [CrossRef]

58) Tel H, Tel H, Esmek M: Quality of sleep in hemodialysis patients. Dial Transplant, 2007, 36: 479-484. [CrossRef]

59) LeBourgeois MK, Giannotti F, Cortesi F, et al.: The relationship between reported sleep quality and sleep hygiene in Italian and American adolescents. Pediatrics, 2005, 115: 257-265. [Medline] [CrossRef]

60) Walker S, Fine A, Kryger MH: Sleep complaints are common in a dialysis unit. Am J Kidney Dis, 1995, 26: 751-756. [Medline] [CrossRef]

61) Fleischmann G, Fillafer G, Matterer H, et al.: Prevalence of chronic kidney disease in patients with suspected sleep apnoea. Nephrol Dial Transplant, 2010, 25: 181-186 [CrossRef]. [Medline]

62) Nicholl DD, Ahmed SB, Loewen AH, et al.: Declining kidney function increases the prevalence of sleep apnea and nocturnal hypoxia. Chest, 2012, 141: 1422-1430. [Medline] [CrossRef] 